\title{
Synthesis of Anemoclemosides A and B, two Saponins Isolated from Anemoclema glaucifolium
}

Bouillon, Marc; Bertocco, Katia; Bischoff, Laura; Buri, Michelle; Davies, lucy Rebecca; Wilkinson, Elizabeth Jane; Lahmann, Martina

\section{European Journal of Organic Chemistry}

DOI:

10.1002/ejoc.202001317

Published: $31 / 12 / 2020$

Peer reviewed version

Cyswllt i'r cyhoeddiad / Link to publication

Dyfyniad o'r fersiwn a gyhoeddwyd / Citation for published version (APA):

Bouillon, M., Bertocco, K., Bischoff, L., Buri, M., Davies, L. R., Wilkinson, E. J., \& Lahmann, M. (2020). Synthesis of Anemoclemosides A and B, two Saponins Isolated from Anemoclema glaucifolium. European Journal of Organic Chemistry, 2020(48), 7470-7473.

https://doi.org/10.1002/ejoc.202001317

\footnotetext{
Hawliau Cyffredinol / General rights

Copyright and moral rights for the publications made accessible in the public portal are retained by the authors and/or other copyright owners and it is a condition of accessing publications that users recognise and abide by the legal requirements associated with these rights.

- Users may download and print one copy of any publication from the public portal for the purpose of private study or research.

- You may not further distribute the material or use it for any profit-making activity or commercial gain

- You may freely distribute the URL identifying the publication in the public portal ?
}

Take down policy

If you believe that this document breaches copyright please contact us providing details, and we will remove access to the work immediately and investigate your claim. 


\section{EurJOC}

European Journal of Organic Chemistry

\section{Phemistry Europe}

European Chemical Societies Publishing

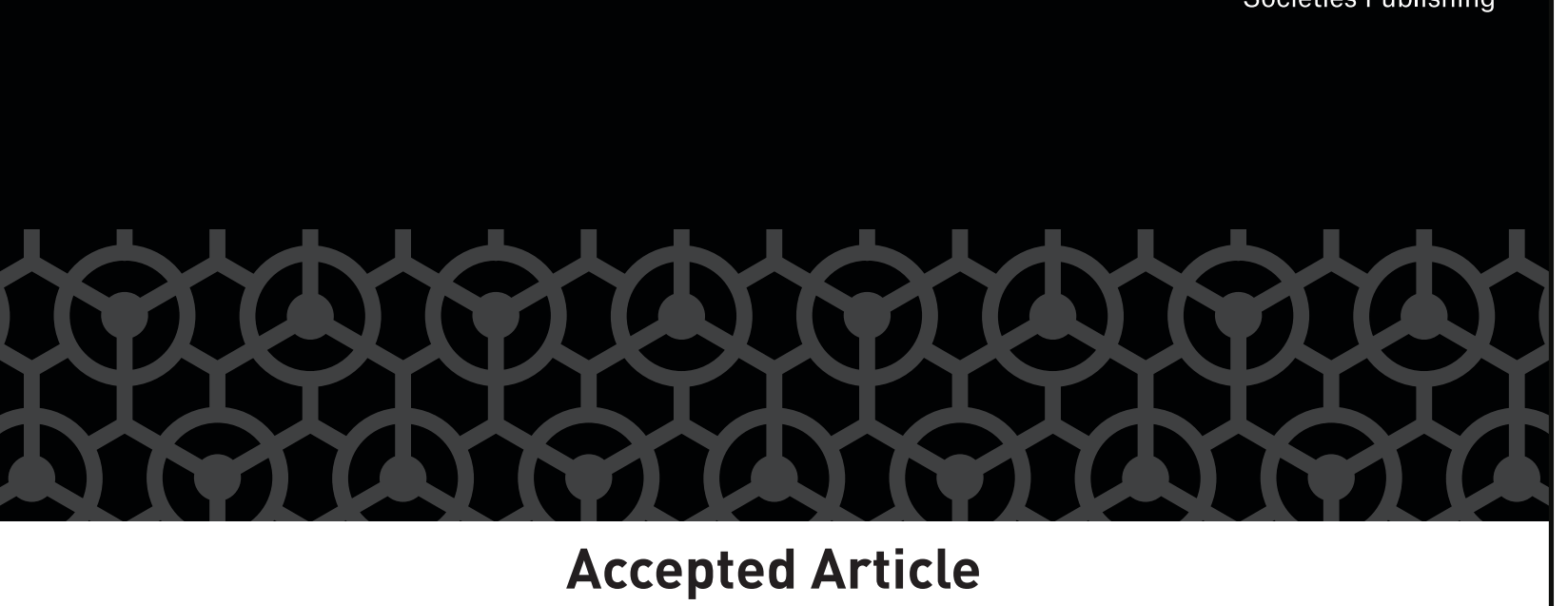

Title: Synthesis of Anemoclemosides A and B, two Saponins Isolated from Anemoclema glaucifolium

Authors: Marc Etienne Bouillon, Katia Bertocco, Laura Bischoff, Michelle Buri, Lucy Rebecca Davies, Elizabeth Jane Wilkinson, and Martina Lahmann

This manuscript has been accepted after peer review and appears as an Accepted Article online prior to editing, proofing, and formal publication of the final Version of Record (VoR). This work is currently citable by using the Digital Object Identifier (DOI) given below. The VoR will be published online in Early View as soon as possible and may be different to this Accepted Article as a result of editing. Readers should obtain the VoR from the journal website shown below when it is published to ensure accuracy of information. The authors are responsible for the content of this Accepted Article.

To be cited as: Eur. J. Org. Chem. 10.1002/ejoc.202001317

Link to VoR: https://doi.org/10.1002/ejoc.202001317 


\title{
Synthesis of Anemoclemosides A and B, two Saponins Isolated from Anemoclema glaucifolium
}

\author{
Marc E. Bouillon, ${ }^{*[a]}$ Katia Bertocco, ${ }^{[a]}$ Laura Bischoff, ${ }^{[a]}$ Michelle Buri, ${ }^{[a]}$ Lucy R. Davies, ${ }^{[a]}$ Elizabeth J. \\ Wilkinson, ${ }^{[a]}$ and Martina Lahmann ${ }^{*[a]}$
}
[a] Dr Marc E. Bouillon, Dr Martina Lahmann
School of Chemistry
Bangor University
Deiniol Road, Bangor, Gwynedd LL57 2UW, Wales, United Kingdom.
E-mail: m.bouillon@bangor.ac.uk, m.lahmann@bangor.ac.uk
URL: https://bangor.academia.edu/MartinaLahmann

Supporting information for this article is given via a link at the end of the document.

\begin{abstract}
Steroidal and triterpenoid saponins are attractive for their wide-ranging pharmacological properties. The triterpenoid saponins Anemoclemoside $A$ and $B$ are root constituents of the Chinese folk medicinal plant Anemoclema glaucifolium (Ranunculaceae). Both compounds feature an unusual cyclic acetal linkage to the carbohydrate L-arabinose in its open chain form rather than the typical glycosidic bond present in normal saponins. The straightforward and scalable syntheses of both saponins starting from $L$-arabinose as well as L-lyxose and L-rhamnose are described.
\end{abstract}

Saponins are a diverse group of natural products widely distributed in the plant kingdom as well as some marine organisms. Their structure is characterized by comprising a triterpene or steroid aglycone and one or more carbohydrate side chains. ${ }^{1}$ Both steroidal and triterpenoid saponins form an interesting class of compounds due to their pharmacological and biological properties und novel synthetic approaches are frequently reported. 2,3,4,5 In 1995, Yamasaki et al. reported the isolation and characterization of two unusual triterpenoid saponins from the roots of Anemoclema glaucifolium (Ranunculaceae), a Chinese folk medicinal plant growing at altitudes between 1600 to $3000 \mathrm{~m}$ in the Yangtse River valley region of China. ${ }^{6}$ Accordingly named Anemoclemosides A and B, these saponins feature an unprecedented cyclic acetal linkage of the triterpene hederagenin to the carbohydrate L-arabinose in its open chain form rather than the typical glycosidic bond present in usual saponins. About 20 years later, Anemoclemoside A was also identified by Kırmızıgül and co-workers to be a constituent in the aerial parts of Cephalaria elazigensis var. purpurea, a perennial medicinal herb belonging to the Dipsacaceae family, widely distributed in southwestern Anatolia, Turkey. ${ }^{7}$ Anemoclemosides $A$ and $B$ are structural isomers of the hederagenin glycosides $\delta$ - and $\alpha$-hederin, two saponins first isolated and characterized from the leaves of common English ivy (Hedera helix, Araliaceae) by Hostettmann. ${ }^{8}$ They were later also found in a multitude of other unrelated plant sources. The glycosidic linkage of saponins is considered as an important feature for their pharmacological and biological properties. However, it is susceptible to enzymatic cleavage under physiological conditions, and loss of activity due to loss of the glycon part has been reported. ${ }^{9}$ The unusual open chain linkage of the Anemoclemosides might not be recognized by common glycosidases and consequently enhance their stability against enzymatic cleavage. To further investigate this feature, larger quantities of this type of saponins were required. Hence, here we present a straightforward and scalable approach for the synthesis of Anemoclemoside B as well as the first synthesis of Anemoclemoside A.

A first synthesis of Anemoclemoside B was reported by $\mathrm{Yu}$ et al. in 2005. ${ }^{10}$ Their synthesis included the formation of the cyclic acetal glycosidic linkage between hederagenin and its disaccharide side chain via a TMS triflate promoted condensation reaction at $-78{ }^{\circ} \mathrm{C}$. Given the optimal geometry of the diol moiety of hederagenin to form chair-shaped cyclic acetals and ketals under acidic catalysis as observed with simple carbonyl compounds like benzaldehyde, we expected the acetal coupling to proceed in the presence of an appropriate Brønsted acid catalyst like PTSA at rt. As a proof of concept, we tested this on the synthesis of Anemoclemoside A with the simpler L-arabinosylidene acetal.

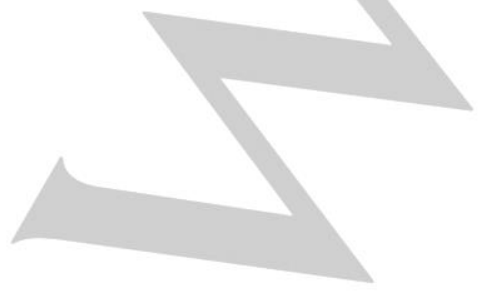




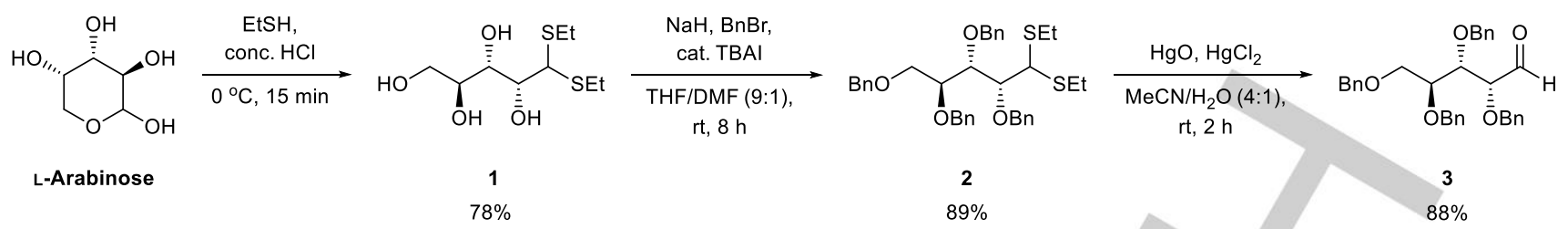

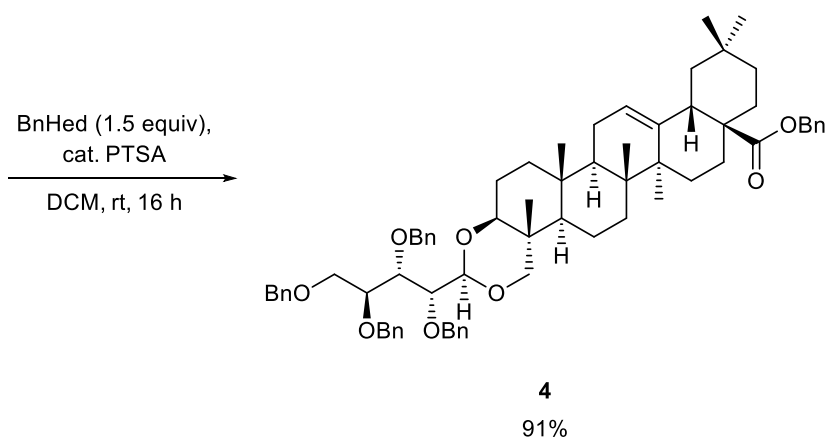

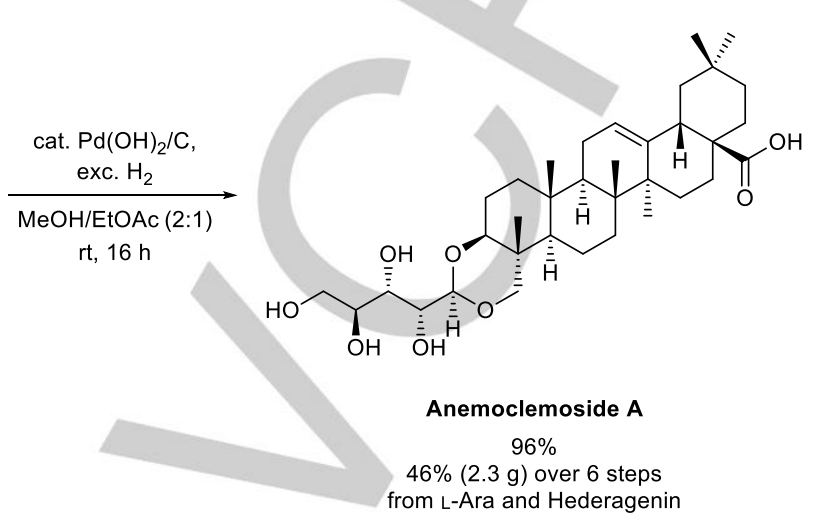

Scheme 1. Synthesis of Anemoclemoside A.

The synthesis of Anemoclemoside A started with the preparation of 2,3,4,5-tetra-O-benzyl-L-arabinose (3) as the glycon building block (Scheme 1). Commercially available L-arabinose was first converted into its open-chain diethyl dithioacetal 1 with ethanethiol in conc. hydrochloric acid followed by O-benzylation with $\mathrm{NaH}, \mathrm{BnBr}$, and TBAl. Cleavage of the thioacetal in $\mathbf{2}$ with mercury(II) chloride in the presence of mercury(II) oxide then provided the fully benzylated L-arabinose aldehyde 3 in $61 \%$ yield over the three steps. Like Yu and co-workers, ${ }^{10}$ we chose the benzyl ester of hederagenin (BnHed) as triterpene building block and coupling partner for the acetal condensation, since unprotected hederagenin is poorly soluble in the reaction solvent dichloromethane. The requisite hederagenin was obtained in multi-gram quantities via the hydrolysis of ivy saponins which, in turn, had been isolated from an ethanolic ivy fruit extract. ${ }^{11}$ Following a procedure by Eldrige et al., ${ }^{12}$ hederagenin was then treated with benzyl bromide in DMF in the presence of potassium carbonate to afford $\mathrm{BnHed}$ in $87 \%$ yield.

For the construction of the cyclic acetal bond, aldehyde 3 and a slight excess (1.5 equiv.) of BnHed were treated with a catalytic amount of PTSA at ambient temperature to give the coupling product 4 in $91 \%$ yield. According to NMR, a single diastereoisomer with the sugar chain in the thermodynamically favored equatorial position was obtained. In a test reaction, Yu et al. observed the formation of an L-arabinosylidene acetal at -78 ${ }^{\circ} \mathrm{C}$ with the tetraol moiety in the axial position. However, they were able to equilibrate to the favored equatorial acetal in the presence of a catalytic amount of TMS triflate at room temperature. ${ }^{10}$ The hydrogenolytic cleavage of all benzyl groups over Pearlman catalyst concluded the synthesis, eventually providing Anemoclemoside $A$ in $46 \%$ overall yield over 6 steps from Larabinose and hederagenin (Scheme 1). As anticipated, the double bond between $\mathrm{C}-12$ and $\mathrm{C}-13$ in the triterpene skeleton was not affected during the deprotection. ${ }^{10}$
Next, we turned to the more challenging synthesis of Anemoclemoside B. As glycosyl donor, 2,3,4-tri-O-acetyl-Lrhamnopyranosyl trichloroacetimidate (5) was synthesised over three steps according to standard procedures (Scheme 2). ${ }^{13}$ The glycosyl acceptor required an 1,3,4,5-O-protected L-arabinose building block with a free $\mathrm{OH}$ group at $\mathrm{C}-2$ to be linked to the $\mathrm{L}$ rhamnose donor.

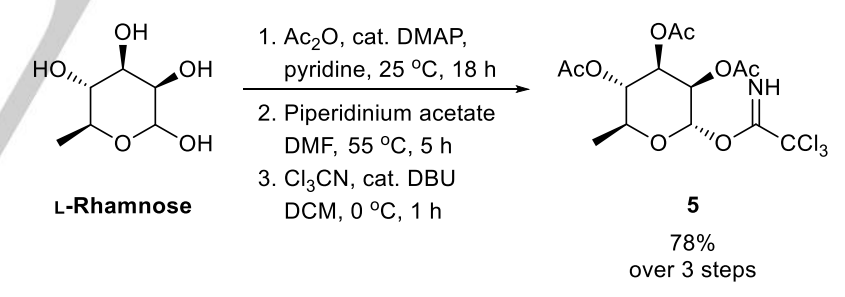

Scheme 2. Synthesis of the L-rhamnose donor 5.

While the thioacetal was convenient as aldehyde precursor in the synthesis of Anemoclemoside A, it is not compatible with the conditions applied in glycosylation reactions with trihaloacetimidates, as $\mathrm{Yu}$ and co-workers already demonstrated..$^{10}$ Thus, we decided to use orthogonally protected 3,4,5-tri-O-benzyl-1-O-TBDPS-L-arabinol (11) as acceptor and to regenerate the aldehyde functionality later in the synthesis. Yet, since the conversion of L-arabinose into this building block requires a 10-step synthesis with a total yield of about $20 \%$, as reported for the 5-O-acetyl-3,4-di-O-benzyl-1-O-TBDPS-Larabinol used in the first Anemoclemoside $B$ synthesis, ${ }^{10}$ we decided to investigate the preparation of $\mathbf{1 1}$ starting from L-lyxose instead (Scheme 3). 

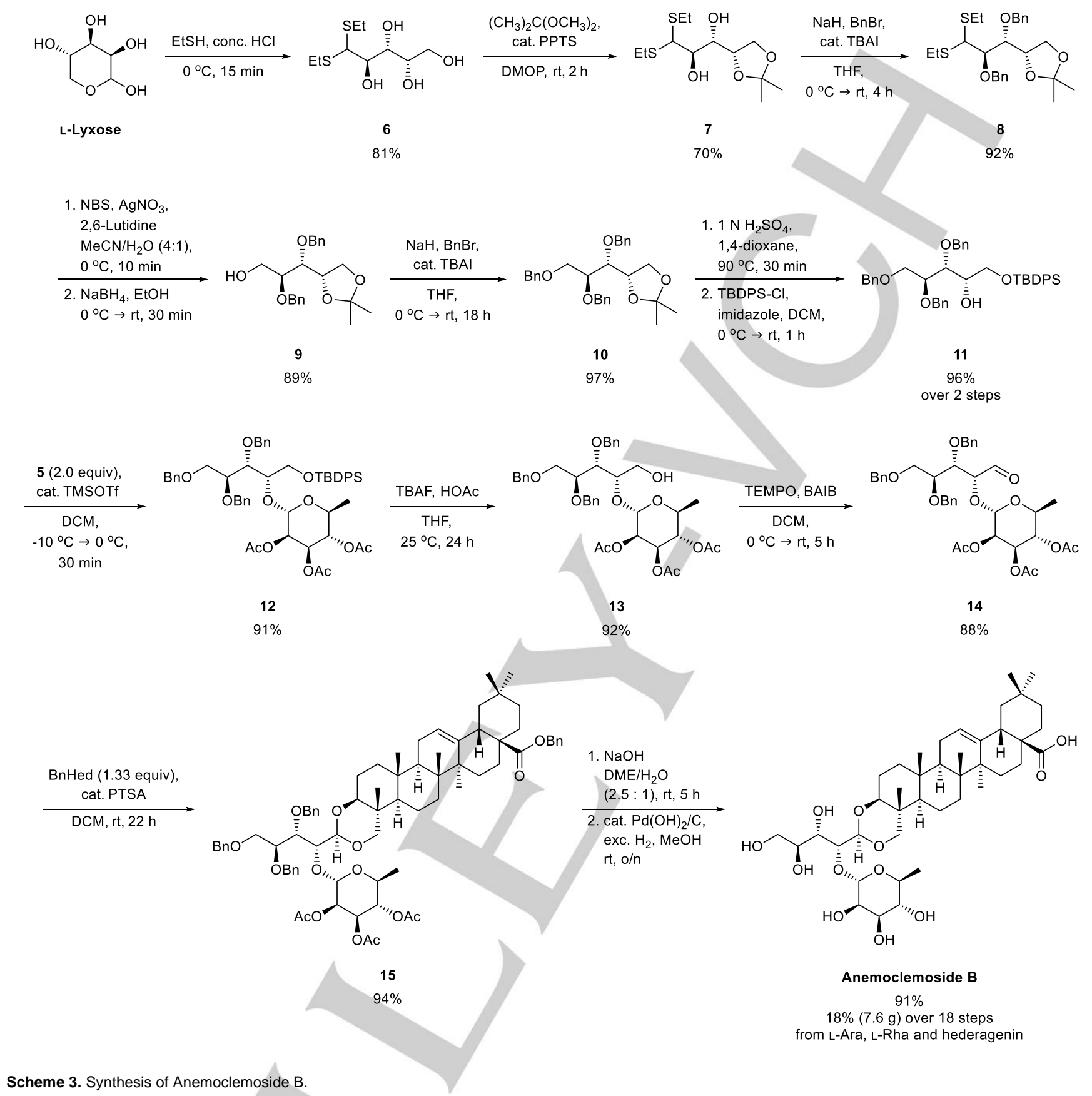

The synthesis of Anemoclemoside B started with the conversion of L-lyxose into its open-chain diethyl dithioacetal 6 in $81 \%$ yield. The following regioselective introduction of the 4,5-Oisopropylidene acetal, however, proved to be challenging. According to Redlich et al., the kinetically controlled reaction of thioacetal 6 with acetone in the presence of $2 \mathrm{~N} \mathrm{HCl}$ at $0-5^{\circ} \mathrm{C}$ should give the desired 4,5-O-isopropylidene acetal within a couple of hours as the major product. ${ }^{14}$ Yet, these conditions preferentially produced the thermodynamically favored 3,4-Oisopropylidene acetal as the main product accompanied by the desired 4,5-derivative and other acetals in minor quantities. Consequently, we performed a series of experiments to find suitable reaction conditions to produce the desired 4,5-acetonide as the main product. Lowering the reaction temperature to $0^{\circ} \mathrm{C}$ had only an effect on the reaction rate but no significant effect on the regioselectivity. Strong acid catalysts (PTSA, CSA) gave complex product mixtures that were separable by column chromatography but produced the desired 4,5-acetonide only in moderate yields ( $\max .40 \%$ ). Side products included the 3,4- and 3,5-O-mono- as well as the 2,3:4,5- and 2,4:3,5-O diisopropylidene acetals. Similar results were obtained when neat acetone or acetone in combination with 2,2-dimethoxypropane or 2-methoxypropene were used. However, when a solution of thioacetal 6 was treated with weakly acidic PPTS in neat 2,2dimethoxypropane for 2 hours, the desired 4,5-O-isopropylidene acetal 7 was obtained in $70 \%$ yield. Longer reaction times led to 
a decrease of the 4,5-acetonide in favor of the 3,4- and 3,5acetonides.

The conversion of $\mathbf{7}$ into the O-benzylated acetonide $\mathbf{1 0}$ was initially planned via a three-step sequence, i.e. hydrolysis of the thioacetal group and reduction of the intermediate aldehyde followed by perbenzylation 4,5-O-isopropylidene-L-lyxitol to yield acetonide 10. However, all attempts to cleave the thioacetal under various conditions resulted in the complete decomposition of the starting material. Therefore, we decided to benzylate the two remaining free hydroxy groups in 7 prior to the thioacetal cleavage. Thioacetal derivatives of pentoses like 8 are known to give the corresponding protected aldehydes in hydrolysis reactions in good yields. ${ }^{15}$ Thus, diol 7 was benzyl protected under standard conditions affording the fully protected L-lyxose derivative 8 in $92 \%$ yield. Initial hydrolysis attempts with $\mathrm{HgCl}_{2} / \mathrm{HgO}$ and NBS resulted in partly concomitant cleavage of the acetonide moiety. Nevertheless, when the hydrolysis of thioacetal 8 was performed with $\mathrm{NBS} / \mathrm{AgNO}_{3}$ buffered with 2,6-lutidine, ${ }^{16}$ alcohol 9 was obtained in $89 \%$ yield after reduction of the intermediate aldehyde with $\mathrm{NaBH}_{4}$. Benzylation of the primary alcohol then yielded the desired acetonide 10 in $97 \%$.

The remaining synthesis steps proceeded smoothly. Hydrolysis of the isopropylidene acetal with dilute aqueous sulfuric acid at 90 ${ }^{\circ} \mathrm{C}$ followed by selective TBDPS protection of the primary alcohol eventually gave the requisite L-arabinol acceptor 11 in $43 \%$ yield over 8 steps. L-Arabinol $\mathbf{1 1}$ was then coupled with the L-rhamnose donor $\mathbf{5}$ in the presence of TMS triflate as Lewis acid catalyst affording disaccharide 12 in a yield of $91 \%$ as a single diastereoisomer. Silyl ether $\mathbf{1 2}$ was subsequently transformed into the required aldehyde $\mathbf{1 4}$ in two steps. First, the TBDPS group was cleaved with TBAF in the presence of excess acetic acid as buffer to prevent acetate migration followed by oxidation of alcohol 13 with TEMPO/BAIB to yield the desired aldehyde 14 in $74 \%$ over two steps. The coupling of disaccharide aldehyde 14 with $\mathrm{BnHed}$ was performed under the same conditions as applied in the synthesis of Anemoclemoside A affording the fully protected Anemoclemoside B precursor 15 in $94 \%$ yield. A two-step deprotection sequence concluded the synthesis of Anemoclemoside B. First, the acetate groups of coupling product 15 were saponified with dilute aqueous $\mathrm{NaOH}$ keeping the benzyl ester intact. The crude semi-deprotected saponin was then debenzylated over Pearlman catalyst with excess hydrogen yielding the desired saponin in $91 \%$. Spectroscopic data of the synthetic saponins matched the data reported for the natural products by Yamasaki et al. ${ }^{6}$

In summary, the saponins Anemoclemoside A and B were synthesised in overall yields of $46 \%$ and $18 \%$ over 6 and 18 steps, respectively. A mild and facile method was employed to construct the characteristic cyclic acetal glycosidic linkage in both saponins via the PTSA catalyzed condensation of benzyl hederagenate with the respective saccharide side chains. $2.3 \mathrm{~g}$ of Anemoclemoside $\mathrm{A}$ and $7.5 \mathrm{~g}$ of Anemoclemoside B were produced in straight forward procedures demonstrating the scalability of this approach.

\section{Acknowledgements}

The authors gratefully acknowledge the financial support by the BEACON initiative, Innovate UK, Bangor University, and the Erasmus+ program (M. Buri).

Keywords: Saponins • Anemoclemosides • Glycosylation • Hederagenin glycosides $•$ Cyclic acetal glycosidic linkage

[1] a) S. B. Mahato, S. Garai, Triterpenoid Saponins in Progress in the Chemistry of Natural Organic Products, (Eds.: W. Herz, G. W. Kirby, R. E. Moore, W. Steglich, C. Tamm), Springer-Verlag, Wien 1998, pp. 1196; (b) M. A. Lacaille-Dubois, Biologically and Pharmacologically Active Saponins from Plants: Recent Advances in Saponins in Food, Feedstuffs and Medicinal Plants, (Eds.: W. Oleszek, A. Marston), Springer Dordrecht, 2000, pp. 205-218; (c) J.-P. Vincken, L. Heng, A. de Groot, H. Gruppen, Phytochemistry 2007, 68, 275-297.

[2] D. Sobolewska, A. Galanty, K. Grabowska, J. Makowska-Wąs, D. Wróbel-Biedrawa, I. Podolak, Phytochem. Rev. 2020, 19, 139-189.

[3] O. Anderson, J. Beckett, C. C. Briggs, L. A. Natrass, C. F. Cranston, E. J. Wilkinson, J. H. Owen, R. Mir Williams, A. Loukaidis, M. E. Bouillon, D. Pritchard, M. Lahmann, M. S. Baird, P. W. Denny, RSC Med. Chem. 2020,11, 833-842.

[4] E. Ramos-Morales, G. de la Fuente, R. J. Nash, R. Braganca, S. Duval, M. E. Bouillon, M. Lahmann, C. J. PLOS ONE 2017, 12, e0184517.

[5] (a) M. Lahmann, H. Gybäck, P. J. Garegg, S. Oscarson, R. Suhr, J. Thiem, Carbohydr. Res. 2002, 337, 2153-2159; (b) B. Yu, J. Sun, X. Yang, Acc. Chem. Res. 2012, 45, 1227-1236; (c) Y. Yang, S. Laval, B. Yu, Adv. Carbohydr. Chem. Biochem. 2014, 71, 137-226.

[6] X.-C. Li, C.-R. Yang, Y.-Q. Liu, R. Kasai, K. Ohtani, K. Yamasaki, K. Miyahara, K. Shingu, Phytochemistry 1995, 39, 1175-1179.

[7] P. Kayce, N. Böke Sarikahya, M. Pekmez, N. Arda, S. Kırmızıgül, Turk. J. Chem. 2017, 41, 345-353.

[8] K. Hostettmann, Helv. Chim. Acta 1980, 63, 606-609.

[9] C. J. Newbold, Assessing Antiprotozoal Agents in In vitro screening of plant resources for extra-nutritional attributes in ruminants: nuclear and related methodologies, (Eds.: P. E. Vercoe, H. P. S. Makkar, A. C. Schlink, Springer Dordrecht, 2010, pp. 47-53.

[10] J. Sun, X. Han, B. Yu, Org. Lett. 2005, 7, 1935-1938.

[11] E. Ramos-Morales, G. de la Fuente, S. Duval, C. Wehrli, M. Bouillon, M. Lahmann, D. Preskett, R. Braganca, C. J. Newbold, Front. Microbiol. 2017, 8 (399).

[12] G. R. Eldridge, R. N. Buckle, M. Ellis, Z. Huang, J. E. Reilly, EP2712863 A1, 2014.

[13] A. M. P. van Steijn, J. P. Kamerling, J. F. G. Vliegenthart, Carbohydr. Res. 1991, 211, 261-277.

[14] O. Kölln, H. Redlich, Synthesis 1996, 826-832.

[15] a) K. M. K. Kutterer, G. Just, Heterocycles 1999, 51, 1409-1420; b) P. Herczegh, I. Kovács, L. Szilágyi, F. Sztaricskai, A. Berecibar, C. Riche, A. Chiaroni, A. Olesker, G. Lukacs, Tetrahedron 1994, 50, 13671-13686; C) F. L. Van Delft, A. Rob, P.M. Valentijn, G. A. Van Der Marel, J. H. Van Boom, J. Carbohydr. Chem. 1999, 18, 165-190.

[16] E. J. Corey, B. W. Erickson, J. Org. Chem. 1971, 36, 3553-3560. 
WILEY-VCH

\section{Entry for the Table of Contents}

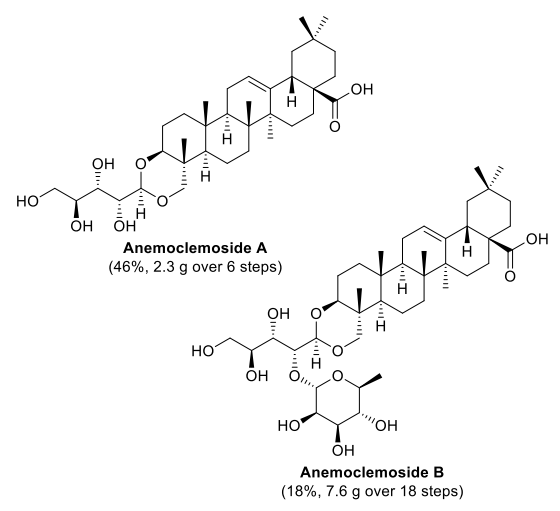

The straightforward and scalable syntheses of the triterpenoid saponins Anemoclemoside A and B are described. Both compounds feature an unusual cyclic acetal linkage to the carbohydrate L-arabinose in its open chain form. A mild and facile method was employed to construct the characteristic cyclic acetal glycosidic linkage in both saponins via the PTSA catalyzed condensation of benzyl hederagenate with the respective saccharide side chains. 